\title{
Blue-Yellow Opponency in Primate S Cone Photoreceptors
}

\author{
Orin S. Packer, ${ }^{1}$ Jan Verweij, ${ }^{2,3}$ Peter H. Li, ${ }^{2,3}$ Julie L. Schnapf, ${ }^{2,3}$ and Dennis M. Dacey ${ }^{1}$ \\ ${ }^{1}$ Department of Biological Structure and the National Primate Research Center, University of Washington, Seattle, Washington 98195, and Departments of \\ ${ }^{2}$ Ophthalmology and ${ }^{3}$ Physiology, University of California, San Francisco, California 94143
}

The neural coding of human color vision begins in the retina. The outputs of long (L)-, middle (M)-, and short (S)-wavelength-sensitive cone photoreceptors combine antagonistically to produce "red-green" and "blue-yellow" spectrally opponent signals (Hering, 1878; Hurvich and Jameson, 1957). Spectral opponency is well established in primate retinal ganglion cells (Reid and Shapley, 1992; Dacey and Lee, 1994; Dacey et al., 1996), but the retinal circuitry creating the opponency remains uncertain. Here we find, from whole-cell recordings of photoreceptors in macaque monkey, that "blue-yellow" opponency is already present in the center-surround receptive fields of $S$ cones. The inward current evoked by blue light derives from phototransduction within the outer segment of the $S$ cone. The outward current evoked by yellow light is caused by feedback from horizontal cells that are driven by surrounding L and M cones. Stimulation of the surround modulates calcium conductance in the center $\mathrm{S}$ cone.

\section{Introduction}

In the primate retina the long $(\mathrm{L})$ and middle $(\mathrm{M})$ cones comprise $\sim 90 \%$ of the total cone population (Ahnelt et al., 1987; Curcio et al., 1991) and are thus relatively accessible for physiological study. $\mathrm{L}$ and $\mathrm{M}$ cones are electrically coupled to each other and to rods via gap junctions over distances of $\sim 10-20 \mu \mathrm{m}$ (Hornstein et al., 2004, 2005). They also receive inhibitory signals from neighboring $\mathrm{L}$ and $\mathrm{M}$ cones over much larger distances via an interneuron, the H1 horizontal cell (Dacey et al., 1996; Packer and Dacey, 2002; Verweij et al., 2003). How these signals are transmitted from horizontal cells to cones is controversial (Hirasawa and Kaneko, 2003; Davenport et al., 2008; Fahrenfort et al., 2009), but the end target is the modulation of calcium channels in the cone synapse (Verweij et al., 1996, 2003).

In contrast, primate short $(\mathrm{S})$ cones comprise only $\sim 10 \%$ of the cones, and thus physiological recordings from $S$ cones are rare (Baylor et al., 1987; Schnapf et al., 1990; Hornstein et al., 2004). Anatomically, S cones contact both $\mathrm{H} 2$ horizontal cells and rods (Ahnelt et al., 1990; Dacey et al., 1996; Goodchild et al., 1996). However, it is not known whether these contacts provide input to $\mathrm{S}$ cones.

Human psychophysical studies indicate that blue-yellow opponency is created by neurons that receive opponent signals from $\mathrm{S}$ cones versus $(\mathrm{L}+\mathrm{M})$ cones (Hurvich and Jameson, 1957; Krauskopf et al., 1982). One such neuron is the small bistratified ganglion cell (Dacey and Lee, 1994). The dendrites of the small

Received Sept. 23, 2009; revised 0ct. 27, 2009; accepted Nov. 23, 2009.

This work was supported by the Paul Kayser International Award from the Retina Research Foundation (D.M.D.), the Research to Prevent Blindness Senior Investigator Award (J.L.S.), a grant from That Man May See Inc. (J.L.S.), National Institutes of Health Grants EY06678 (D.M.D.), EY07642, (J.L.S.), and RR00166 (the National Primate Research (enter at the University of Washington), and Vision Research Core Grants EY01730 (D.M.D.) and EY02162 (J.L.S.). We thank Dr. Edward N. Pugh for insightful discussions, Julian Vrieslander for programming assistance, and Toni Haun and Beth Peterson for technical assistance.

Correspondence should be addressed to Dr. Dennis M. Dacey, Department of Biological Structure, University of Washington, Seattle, WA 98195. E-mail: dmd@u.washington.edu.

DOI:10.1523/JNEUROSCI.4738-09.2010

Copyright $\odot 2010$ the authors $\quad 0270-6474 / 10 / 300568-05 \$ 15.00 / 0$ bistratified cell stratify in both the ON and OFF portions of the inner plexiform layer, suggesting that the blue-ON and yellowOFF responses reflect synaptic input from S-ON bipolar cells and $(\mathrm{L}+\mathrm{M})$-OFF bipolar cells, respectively (Dacey and Lee, 1994; Calkins et al., 1998). However, in a recent study (Field et al., 2007), both the blue and yellow responses were abolished when the ON pathway was selectively blocked by DL-2-amino-4phosphono-butyric acid (L-AP4), suggesting that both the blue and the yellow signals arrive via the S-ON bipolar cell. Since this bipolar cell contacts $\mathrm{S}$ but not $\mathrm{L}$ or $\mathrm{M}$ cones, it was inferred that the $(\mathrm{L}+\mathrm{M})$ signal was already present in $\mathrm{S}$ cones, and that it arose from horizontal cell feedback to $S$ cones. In contrast, a later study found that L-AP4 selectively blocked the S-ON and spared the $(\mathrm{L}+\mathrm{M})$-OFF responses, consistent with the $(\mathrm{L}+\mathrm{M})$ signal arriving via the ( $\mathrm{L}+\mathrm{M})$-OFF bipolar cell (Crook et al., 2009). Thus it remains uncertain whether blue-yellow opponency in the retina arises from horizontal cell feedback to cones, from the convergence of ON- and OFF-bipolar cell inputs to the ganglion cell, or from some combination of both.

To address this question, we asked whether primate $S$ cone photoreceptors showed evidence of center-surround organization as previously found for $\mathrm{L}$ and $\mathrm{M}$ cones and, if so, whether spectral opponency was present. To characterize their spatial and spectral receptive field properties, we selectively targeted the minority $S$ cones for whole-cell voltage-clamp recordings (Verweij et al., 2003) in isolated macaque monkey retina.

\section{Materials and Methods}

Eyes from Old World monkeys (Macaca nemestrina, Macaca fascicularis, and Papio cynocephalus anubis) were obtained from tissue distribution programs at the Washington National Primate Research Center and the California National Primate Research Center. The combined retinachoroid-pigment epithelium was dissected and incubated in the dark for at least $1 \mathrm{~h}$ in bicarbonate-buffered Ames medium at $36^{\circ} \mathrm{C}$. Small portions of retina were isolated and placed photoreceptor-side up in a recording chamber superfused with Ames medium. Single cones were voltage-clamped with whole-cell patch electrodes (Verweij et al., 2003). In most experiments the electrode solution contained (in $\mathrm{mm}$ ) 99 
K-gluconate, $32 \mathrm{KCl}, 4.5 \mathrm{MgCl}_{2}, 10 \mathrm{HEPES}, 3 \mathrm{ATP}-\mathrm{Na}_{2}, 1 \mathrm{GTP}-\mathrm{Na}_{3}$, and 5 BAPTA- $\mathrm{K}_{4}$. When measuring calcium currents, $\mathrm{K}$-gluconate was replaced with Cs-gluconate ( $99 \mathrm{~mm})$, and $\mathrm{KCl}$ was replaced with $\mathrm{CsCl}(22$ $\mathrm{mm})$ and tetraethylammonium chloride (TEA-Cl) $(10 \mathrm{~mm})$. Voltages were corrected for electrode junction potential and series resistance. Light stimuli were created with a four channel light-emitting diode (LED)-based stimulator (Pokorny et al., 2004) or a three-primary digital light projector (Crook et al., 2009). Unless indicated otherwise, stimulus radius was $1 \mathrm{~mm}$. Descriptions of the optics, cone-isolating stimuli, and calculations of cone quantal catch rates are given previously (Crook et al., 2009).

\section{Results}

Cone identification and "blue" receptive field center

Anatomical features were used to specifically target $S$ cones for recording. The maximal inner diameter of $S$ cone inner segments was smaller than that of $\mathrm{L}$ and $\mathrm{M}$ cones, and $\mathrm{S}$ cones tended to disrupt the regular spatial array of cones (Ahnelt et al., 1990; Curcio et al., 1991) (Fig. 1A, arrow). Cone identity was determined from the relative response amplitudes to light pulses from red, green, cyan, and blue LEDs and further confirmed with stimuli that independently modulated the photon catch rate of the S, M, or L photopigment (Baylor et al., 1987; Crook et al., 2009) (Fig. $1 B$ ). Consistent with previous observations (Hornstein et al., 2004; Li and DeVries, 2004), the spectral sensitivity of S cones showed no evidence for electrical coupling to neighboring $\mathrm{L}$ and $\mathrm{M}$ cones (Fig. $1 B$ ).

To determine whether $S$ cones were electrically coupled to neighboring $S$ cones, the receptive field size was measured with $S$ photopigment-isolating gratings that were modulated sinusoidally in space and drifted across the retina at $2 \mathrm{~Hz}$. Assuming response linearity, peak response amplitude $(A)$ as a function of spatial frequency $(f)$ is given by the two-dimensional Fourier transform of the receptive field sensitivity profile, which simplifies to a zero-order Hankel transform for a radially symmetric receptive field (Bracewell, 1999). For a receptive field profile that declines exponentially with radial distance from the center,

$$
A(f)=k\left[(1 / \lambda)^{2}+(2 \pi f)^{2}\right]^{-3 / 2}
$$

where $\lambda$ is the exponential length constant and $k$ is a scalar. In 13 $\mathrm{S}$ cones the best fitting $\lambda$ was $5.3 \pm 3.4 \mu \mathrm{m}$ (mean $\pm \mathrm{SD}$ ). The choice of an exponential function was somewhat arbitrary; similarly good fits were obtained with a Gaussian function. The receptive field sizes are larger than would be expected for a single cone, however spatial resolution of the field size appears to have been limited by our optics as evidenced by the subset of 3 cones where image focus was optimized with a high numeric aperture water-immersion lens. In these cones $\lambda$ ranged from 1.9 to 4.1 $\mu \mathrm{m}$ (Fig. $1 C$ ). Nevertheless, given that all S cones were recorded in far peripheral retina where their average separation is $50-70$ $\mu \mathrm{m}$ (Curcio et al., 1991), the receptive field sizes from all 13 cones indicate that there is no significant electrical coupling between $\mathrm{S}$ cones.

\section{"Yellow" inhibitory surround arises from horizontal cell feedback}

The center-surround opponency of cone receptive fields results from feedback inhibition from horizontal cells (Baylor et al., 1971; Verweij et al., 2003). In primate L and M cones, the feedback signal is enhanced by holding the membrane potential at $-40 \mathrm{mV}$ and by including elevated chloride $\left(\mathrm{E}_{\mathrm{Cl}}=-30 \mathrm{mV}\right)$ and calcium chelator BAPTA in the patch solution (Verweij et al., 2003). Using these conditions we observed clear blue-center
A

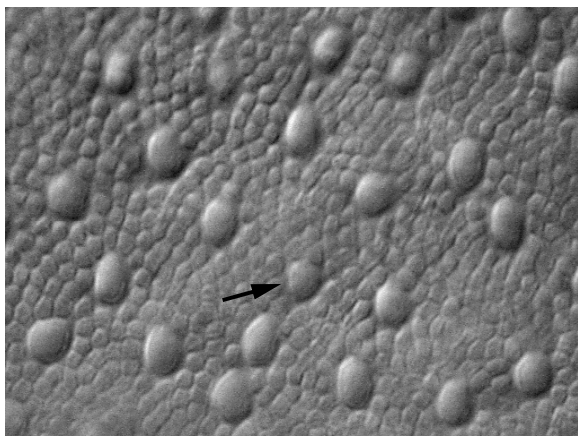

$1 \overline{0 \mu \mathrm{m}}$

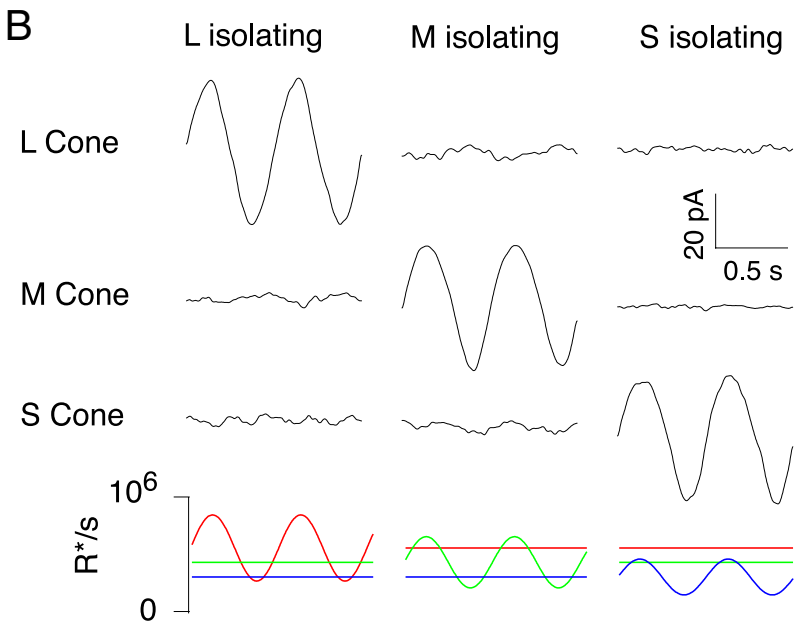

C
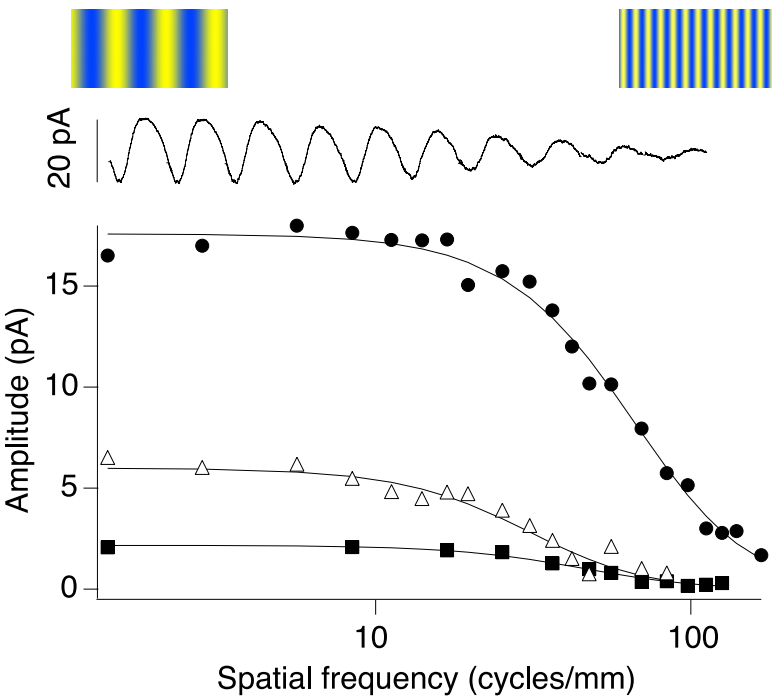

Figure 1. S cone identification. $A$, Infrared image of retina focused on rod (small) and cone (large) inner segments. Arrow indicates $S$ cone. $\boldsymbol{B}$, Membrane current response to coneisolating stimuli. Colored lines plot photoisomerization $/ \mathrm{S}\left(R^{*} / \mathrm{S}\right)$ in $\mathrm{L}(\mathrm{red}), \mathrm{M}$ (green), and $\mathrm{S}$ (blue) cones. C, Top: Concatenated responses to increasing spatial frequencies. Bottom: Response amplitude (symbols) versus spatial frequency from $3 \mathrm{~S}$ cones. Lines plot Equation 1 with $\lambda=1.9(\bigcirc), 4.1(\triangle)$, and $2.8(\square) \mu \mathrm{m}$. Membrane potential $-60 \mathrm{mV}$. S cone sinusoidal modulated stimulus with mean photoisomerizations/s of $1.6 \times 10^{6}, 1.2 \times 10^{6}$, and $5.9 \times$ $10^{5}$ in L, M, and S cones, respectively. S cone Michelson contrast $94 \%$.

yellow-surround opponency in S cones. Blue light that strongly activated $S$ cone photopigment evoked outward currents, while yellow light that preferentially activated surrounding $\mathrm{L}$ and $\mathrm{M}$ cones evoked inward currents (Fig. $2 A)(n=35)$. Measurements of long-wavelength sensitivity of the inward current confirmed 
that both $\mathrm{L}$ and $\mathrm{M}$ cones contribute to the opponent surround of S cones $(n=7$, data not shown). The only known pathway by which $\mathrm{L}$ and $\mathrm{M}$ cones could transmit an opponent signal to $\mathrm{S}$ cones is via H2 horizontal cells (Dacey et al., 1996). Since H2 horizontal cells receive input from all three cone spectral types (Dacey et al., 1996), the opponent surround of an $\mathrm{S}$ cone would be expected to have an $\mathrm{S}$ cone component as well. While none was observed, the lack of a demonstrable contribution from $\mathrm{S}$ cones in the surround may simply reflect our inability to resolve a small inhibitory $S$ cone signal when superimposed on a large excitatory $\mathrm{S}$ cone phototransduction signal.

If the opponent surround response is mediated by horizontal cells, it should be blocked by CNQX (6-cyano-7-nitroquinoxaline-2,3-dione), an antagonist that blocks glutamate receptors on horizontal cells (Haverkamp et al., 2001a,b; Verweij et al., 2003). Figure 2 shows that the surround response was indeed reversibly blocked by superfusion of $20 \mu \mathrm{M}$ CNQX (Fig. $2 B, n=2$ ), consistent with horizontal cells mediating the response.

\section{Calcium dependence of the inhibitory surround}

The voltage dependence of the surround response (Fig. 3) indicates that surround stimulation modulates calcium conductance in $\mathrm{S}$ cones. To measure the calcium current, voltage-activated potassium and $I_{\mathrm{h}}$ channels and calcium-activated chloride channels were blocked by including cesium, TEA, and BAPTA in the electrode solution (Yagi and Macleish, 1994). The remaining voltage-activated current was inward (Fig. 3A,B) and displayed the kinetics and voltage-sensitivity of L-type calcium channels (Barnes and Hille, 1989; Yagi and Macleish, 1994; Verweij et al., 1996). Measureable currents were observed at membrane potentials positive to $-55 \mathrm{mV}$. The current was sustained for membrane potentials up to $-15 \mathrm{mV}$; larger depolarizations evoked inactivation (data not shown). Stimulation of the surround with yellow light increased the maximal inward current and shifted its voltage activation range to more negative potentials (Fig. $3 A, B$ ). The surround-evoked enhancement of the current was greatest at a membrane potential of $\sim-40 \mathrm{mV}$ (Fig. 3C) $(n=6)$. The voltage dependence of the surround was tested a second way: the amplitude of the response to a yellow light flash was measured as a function of steady-state membrane potential. Response amplitude was maximal at $-42 \pm 4 \mathrm{mV}$ (mean $\pm \mathrm{SD} ; n=41)$. Thus surround activation was optimal at a voltage close to the physiological dark resting potential of $\sim-45 \mathrm{mV}$. These data are consistent with the idea that the surround-evoked inward current reflects the modulation of a voltage-activated calcium current (Verweij et al., 1996).

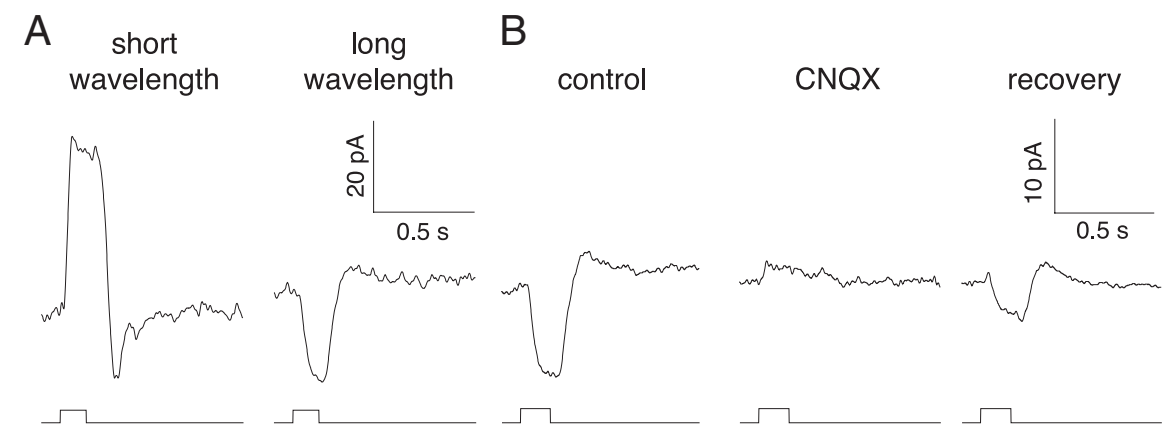

Figure 2. S cone chromatic opponency is created by horizontal cell feedback. $A$, Short-wavelength blue light evokes outward current; long-wavelength yellow light evokes inward current. $\boldsymbol{B}$, Inward current evoked by yellow light is blocked by $20 \mu \mathrm{M}$ CNQX. $A, B$, Membrane potential voltage-clamped at $-40 \mathrm{mV}$. Stimulus monitor below current traces. Photoisomerizations $/ \mathrm{s}$ in $\mathrm{L}, \mathrm{M}$, and $S$ cones, respectively, are: $1.2 \times 10^{6}, 2.0 \times 10^{6}$, and $4.3 \times 10^{6}$ (blue), and $2.8 \times 10^{6}, 1.8 \times 10^{6}$, and $1.9 \times 10^{3}$ (yellow).

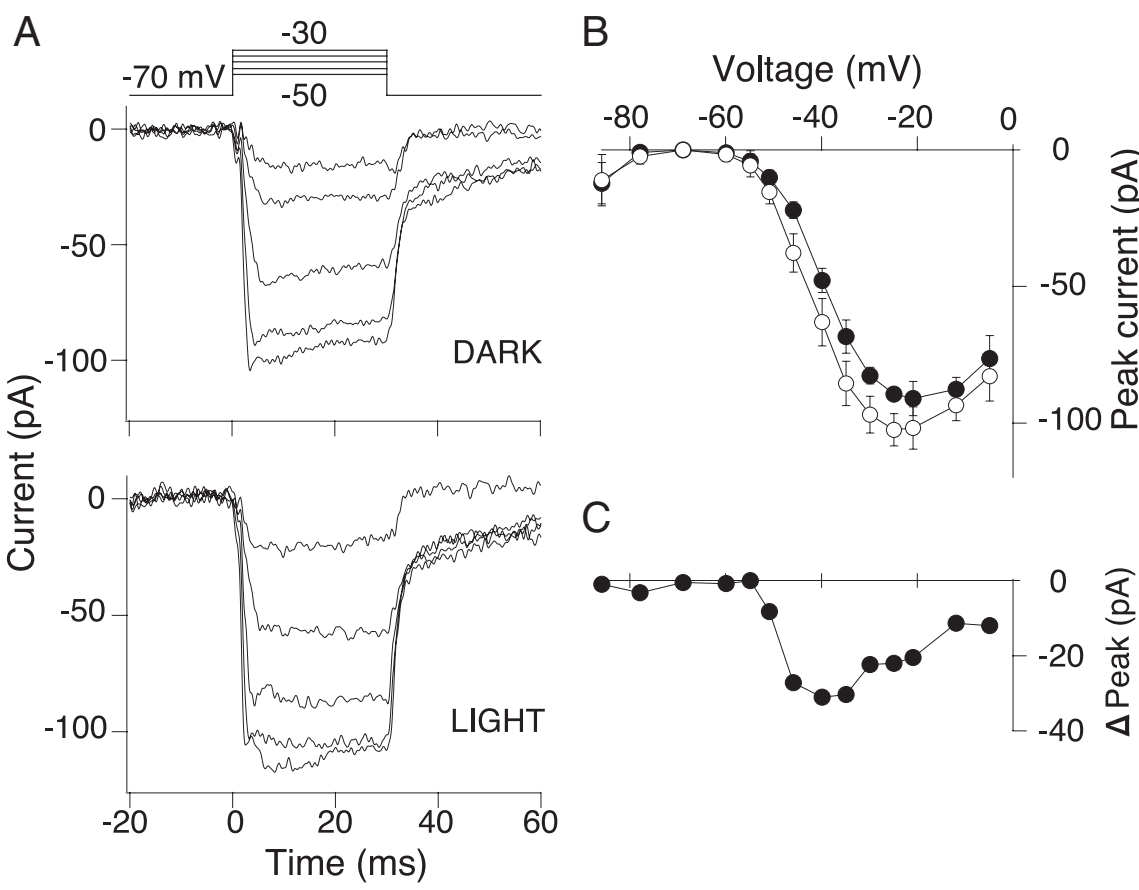

Figure 3. Opponent surround activates calcium currents. $\boldsymbol{A}$, Voltage-activated calcium currents increased in steady yellow light. Membrane potential stepped from $-70 \mathrm{mV}$ to between -85 and $-5 \mathrm{mV}$. Responses shown for steps to between -50 and -30 $\mathrm{mV}$. Voltage monitor above current traces. Calcium currents were isolated by including Cs and TEA in the patch solution (see Materials and Methods) and by subtraction of the capacitance and linear leak currents. Dark measurements were averaged from Points averaged across 7 trials from 3 cones; bars indicate SDs. C, Light-dark difference of calcium currents. $\boldsymbol{A}$-C, Light evoked $2.8 \times 10^{6}, 1.8 \times 10^{6}$, and $1.9 \times 10^{3}$ photoisomerizations/s in the $L, M$, and S cones.

In addition to its modulation by horizontal cell feedback, calcium conductance in the cone synapse has also been shown in ground squirrel to be modulated by protons that are released via exocytosis of the cone's own synaptic vesicles (DeVries, 2001). The light modulation of the calcium conductance that we observe here however cannot be accounted for by such a mechanism because the cone was voltage-clamped and hence voltage-dependent exocytosis was held constant across dark/light conditions. This does not however rule out an in vivo role for local vesicle-based modulation of calcium conductance in the $\mathrm{S}$ cone synapse.

\section{Spatial properties of inhibitory surround}

The spatial extent of the opponent surround was examined with annular stimuli. The annulus was composed of either yellow light 
A

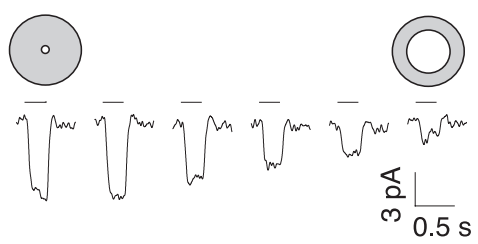

B

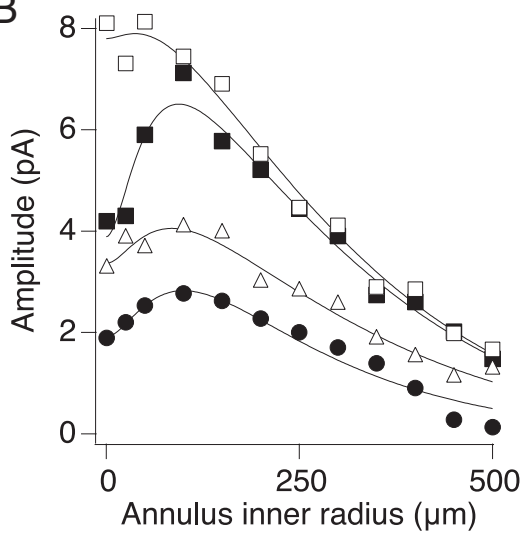

Figure 4. Size of opponent surround. $A$, Responses to flashed annuli; inner radius $25-500$ $\mu \mathrm{m}$, outer radius $1 \mathrm{~mm}$. Flash monitor above current traces. $\boldsymbol{B}$, Peak response amplitude versus inner radius from 4 cones. Annular flash: Long-wavelength flash from darkness $(\square, \boldsymbol{\square}, \triangle)$ evoked $3.5 \times 10^{6}, 2.6 \times 10^{6}$, and $1.1 \times 10^{5}$ photoisomerizations/s in L, M, and $S$ cones, or $L+M$ cone modulation $\left(-\right.$ ), with background rate of $\sim 1.5 \times 10^{5}$ photoisomerizations $/ \mathrm{s}$ for $L, M$, and $S$ cones and a flashed increment of $5.7 \times 10^{6}(L), 5.6 \times 10^{6}(M)$, and $0(S)$. Membrane potential $-40 \mathrm{mV}$. Lines are Equation 2 with $\lambda_{5}=172(\square), 176(\square), 180$ $(\triangle)$, or $140(\bigcirc) \mu \mathrm{m}$.

that preferentially activated $\mathrm{L}$ and $\mathrm{M}$ photopigment, or an $(\mathrm{L}+\mathrm{M})$ cone-isolating stimulus. The annulus inner radius $r_{\mathrm{I}}$ varied while the outer radius $r_{\mathrm{O}}$ was fixed at $0.5-1 \mathrm{~mm}$. In most cells response amplitude varied nonmonotonically with radius (Fig. 4), indicating that the annulus not only stimulated the surround but also weakly stimulated a "center" mechanism whose polarity was opposite that of the surround. Assuming that center and surround sensitivity profiles decline exponentially with distance from the center, the peak response amplitude $R$ is given by the following:

$$
\begin{aligned}
& R=k_{\mathrm{S}}\left[e^{-r_{\mathrm{I}} / \lambda_{\mathrm{S}}}\left(1+\frac{r_{\mathrm{I}}}{\lambda_{\mathrm{S}}}\right)-e^{-r_{\mathrm{O}} / \lambda_{\mathrm{S}}}\left(1+\frac{r_{\mathrm{O}}}{\lambda_{\mathrm{S}}}\right)\right] \\
&-k_{\mathrm{C}}\left[e^{-r_{\mathrm{I}} / \lambda_{\mathrm{C}}}\left(1+\frac{r_{\mathrm{I}}}{\lambda_{\mathrm{C}}}\right)-e^{-r_{\mathrm{O}} / \lambda_{\mathrm{C}}}\left(1+\frac{r_{\mathrm{O}}}{\lambda_{\mathrm{C}}}\right)\right]
\end{aligned}
$$

where $\lambda_{\mathrm{C}}$ and $\lambda_{\mathrm{S}}$ are exponential length constants for the center and surround, and $k_{\mathrm{C}}$ and $k_{\mathrm{S}}$ are scalars. The best-fitting exponential length constant $\lambda_{\mathrm{S}}$ for the surround component was $131 \pm 50 \mu \mathrm{m}$ (mean $\pm \mathrm{SD} ; n=12)$. This is close to the value of $144 \mu \mathrm{m}$ found to describe the exponential sensitivity profile of a macaque H2 horizontal cell (Dacey, 2000). Hence, the spatial extent of the opponent surround we observed here is consistent with feedback inhibition from horizontal cells.

The weak center component of the $\mathrm{S}$ cone receptive field $\left(\lambda_{\mathrm{C}}=31 \pm 13 \mu \mathrm{m}\right)$ could result from either direct stimulation of the $S$ cone itself or rod input through gap junctions (Ahnelt et al., 1990; Schneeweis and Schnapf, 1995). Direct stimulation of the S cone is unlikely however because the center component was present with $(\mathrm{L}+\mathrm{M})$ stimuli that modulated rod but not $\mathrm{S}$ cone photopigment (Fig. 4, O). That this putative rod input was not observed with the $S$ cone grating stimulus (Fig. 1) probably re- flects the fact that the rods were more light adapted, the stimulus contrast was lower for rods, and the grating strongly activated the $S$ cone outer segment directly.

\section{Discussion}

We have determined that horizontal cell feedback to $S$ cones creates the first stage of blue-yellow opponency in the primate retina. The maximal response amplitudes of the $S$ cone center and $(\mathrm{L}+\mathrm{M})$ cone surround were roughly comparable when recorded at a membrane potential of $-40 \mathrm{mV}$ (Fig. $2 \mathrm{~A}$ ). However in the physiological range between -45 and $-70 \mathrm{mV}$, center responses remained largely unchanged (data not shown) (Miller and Korenbrot, 1993) but surround responses were significantly reduced (Fig. 3C). Nonetheless, even with this reduced size the surround is expected to be a potent modulator of synaptic transmission because it directly modulates calcium current at the synapse. In contrast, only a small fraction of the current evoked by center stimulation is carried by calcium. Consequently, although the surround response is proportionately small under physiological conditions, it will have a disproportionately large effect on the synaptic transmission of cone signals.

The calcium dependence of the opponent yellow surround may help explain the paradoxical psychophysical finding that yellow light can increase sensitivity to blue light - a flash of blue light becomes less visible when a steady blue background is turned on, but becomes more visible when yellow light is added to the blue background (Pugh and Mollon, 1979; Polden and Mollon, 1980; Pugh and Larimer, 1980). The S cone responses we describe here suggest a possible explanation: the blue background hyperpolarizes $\mathrm{S}$ cones, reducing the slope conductance of the calcium current and thus reducing synaptic gain. The addition of yellow light activates horizontal cell feedback, increasing the calcium current and its slope conductance, and thereby restoring synaptic gain (VanLeeuwen et al., 2009).

Our results indicate that opponent spectral interactions are created at two synaptic levels in the retina. At the $S$ cone synapse, horizontal cell feedback creates both blue-yellow chromatic opponency and center-surround spatial opponency. Surprisingly, these large opponent surrounds are not retained by S-conedriven ganglion cells where the yellow-OFF and blue-ON fields are more comparable in spatial extent (de Monasterio, 1978; Solomon et al., 2005; Field et al., 2007; Crook et al., 2009). Why is the spatial opponency of $\mathrm{S}$ cones no longer evident in ganglion cells? Both the S-ON and the ( $\mathrm{L}+\mathrm{M})$-OFF bipolar cells that comprise the input to the $\mathrm{S}$-cone-driven ganglion cell have themselves opponent $(\mathrm{L}+\mathrm{M})$ surrounds, these surrounds reflecting horizontal cell feedback to cones. When signals from the ON- and OFF-bipolar cells are combined by the ganglion cell, the surrounds would be expected to cancel, thereby creating pure chromatic opponency with little spatial opponency (Crook et al., 2009). These receptive field properties are retained by the downstream neurons of the lateral geniculate nucleus (Wiesel and Hubel, 1966; Derrington et al., 1984). Thus it appears that the main function of yellow opponency in S cones is not to create a chromatic signal, because that function is recapitulated by circuitry in the inner retina, but rather to estimate and offset average background intensity and chromaticity so as to optimize transmission of short wavelength signals across the $S$ cone synapse. The use of presynaptic inhibition to enhance synaptic gain may be a common modulatory mechanism used by the nervous system to counteract synaptic saturation and to optimize synaptic transmission. For example, activation of presynaptic $\mathrm{GABA}_{\mathrm{B}}$ re- 
ceptors reduces synaptic depression in auditory nerve fibers (Brenowitz et al., 1998).

\section{References}

Ahnelt P, Keri C, Kolb H (1990) Identification of pedicles of putative bluesensitive cones in the human retina. J Comp Neurol 293:39-53.

Ahnelt PK, Kolb H, Pflug R (1987) Identification of a subtype of cone photoreceptor, likely to be blue sensitive, in the human retina. J Comp Neurol 255:18-34.

Barnes S, Hille B (1989) Ionic channels of the inner segment of tiger salamander cone photoreceptors. J Gen Physiol 94:719-743.

Baylor DA, Fuortes MG, O'Bryan PM (1971) Receptive fields of cones in the retina of the turtle. J Physiol 214:265-294.

Baylor DA, Nunn BJ, Schnapf JL (1987) Spectral sensitivity of cones of the monkey Macaca fascicularis. J Physiol 390:145-160.

Bracewell RD (1999) The Hankel transform. In: The Fourier transform and its application. Ed 3, pp 244-250. New York: MacGraw-Hill.

Brenowitz S, David J, Trussell L (1998) Enhancement of synaptic efficacy by presynaptic GABA(B) receptors. Neuron 20:135-141.

Calkins DJ, Tsukamoto Y, Sterling P (1998) Microcircuitry and mosaic of a blue-yellow ganglion cell in the primate retina. J Neurosci 18:3373-3385.

Crook JD, Davenport CM, Peterson BB, Packer OS, Detwiler PB, Dacey DM (2009) Parallel ON and OFF cone bipolar inputs establish spatially coextensive receptive field structure of blue-yellow ganglion cells in primate retina. J Neurosci 29:8372-8387.

Curcio CA, Allen KA, Sloan KR, Lerea CL, Hurley JB, Klock IB, Milam AH (1991) Distribution and morphology of human cone photoreceptors stained with anti-blue opsin. J Comp Neurol 312:610-624.

Dacey DM (2000) Parallel pathways for spectral coding in primate retina. Annu Rev Neurosci 23:743-775.

Dacey DM, Lee BB (1994) The 'blue-on' opponent pathway in primate retina originates from a distinct bistratified ganglion cell type. Nature 367:731-735.

Dacey DM, Lee BB, Stafford DK, Pokorny J, Smith VC (1996) Horizontal cells of the primate retina: cone specificity without spectral opponency. Science 271:656-659.

Davenport CM, Detwiler PB, Dacey DM (2008) Effects of pH buffering on horizontal and ganglion cell light responses in primate retina: evidence for the proton hypothesis of surround formation. J Neurosci 28:456-464.

de Monasterio FM (1978) Properties of ganglion cells with atypical receptive-field organization in retina of macaques. J Neurophysiol 41:1435-1449.

Derrington AM, Krauskopf J, Lennie P (1984) Chromatic mechanisms in lateral geniculate nucleus of macaque. J Physiol 357:241-265.

DeVries SH (2001) Exocytosed protons feedback to suppress the Ca2+ current in mammalian cone photoreceptors. Neuron 32:1107-1117.

Fahrenfort I, Steijaert M, Sjoerdsma T, Vickers E, Ripps H, van Asselt J, Endeman D, Klooster J, Numan R, ten Eikelder H, von Gersdorff H, Kamermans M (2009) Hemichannel-mediated and pH-based feedback from horizontal cells to cones in the vertebrate retina. PLoS One 4:e6090.

Field GD, Sher A, Gauthier JL, Greschner M, Shlens J, Litke AM, Chichilnisky EJ (2007) Spatial properties and functional organization of small bistratified ganglion cells in primate retina. J Neurosci 27:13261-13272.

Goodchild AK, Chan TL, Grünert U (1996) Horizontal cell connections with short-wavelength-sensitive cones in macaque monkey retina. Vis Neurosci 13:833-845.

Haverkamp S, Grünert U, Wässle H (2001a) The synaptic architecture of
AMPA receptors at the cone pedicle of the primate retina. J Neurosci 21:2488-2500

Haverkamp S, Grünert U, Wässle H (2001b) Localization of kainate receptors at the cone pedicles of the primate retina. J Comp Neurol 436:471-486

Hering E (1878) Zur Lehre vom Lichtsinne. Vienna: Carl Gerold's Sohn.

Hirasawa H, Kaneko A (2003) pH changes in the invaginating synaptic cleft mediate feedback from horizontal cells to cone photoreceptors by modulating Ca2 + channels. J Gen Physiol 122:657-671.

Hornstein EP, Verweij J, Schnapf JL (2004) Electrical coupling between red and green cones in primate retina. Nat Neurosci 7:745-750.

Hornstein EP, Verweij J, Li PH, Schnapf JL (2005) Gap-junctional coupling and absolute sensitivity of photoreceptors in macaque retina. J Neurosci 25:11201-11209.

Hurvich LM, Jameson D (1957) An opponent-process theory of color vision. Psychol Rev 64:384-404.

Krauskopf J, Williams DR, Heeley DW (1982) Cardinal directions of color space. Vision Res 22:1123-1131.

Li W, DeVries SH (2004) Separate blue and green cone networks in the mammalian retina. Nat Neurosci 7:751-756.

Miller JL, Korenbrot JI (1993) In retinal cones, membrane depolarization in darkness activates the cGMP-dependent conductance. A model of Ca homeostasis and the regulation of guanylate cyclase. J Gen Physiol 101:933-960.

Packer OS, Dacey DM (2002) Receptive field structure of H1 horizontal cells in macaque monkey retina. J Vis 2:272-292.

Pokorny J, Smithson H, Quinlan J (2004) Photostimulator allowing independent control of rods and the three cone types. Vis Neurosci 21:263-267.

Polden PG, Mollon JD (1980) Reversed effect of adapting stimuli on visual sensitivity. Proc R Soc Lond B Biol Sci 210:235-272.

Pugh EN Jr, Larimer J (1980) Test of the identity of the site of blue/yellow hue cancellation and the site of chromatic antagonism in the $\pi_{1}$ pathway. Vision Res 20:779-788.

Pugh EN Jr, Mollon JD (1979) A theory of the $\pi_{1}$ and $\pi_{3}$ color mechanisms of Stiles. Vision Res 19:293-312.

Reid RC, Shapley RM (1992) Spatial structure of cone inputs to receptive fields in primate lateral geniculate nucleus. Nature 356:716-718.

Schnapf JL, Nunn BJ, Meister M, Baylor DA (1990) Visual transduction in cones of the monkey Macaca fascicularis. J Physiol 427:681-713.

Schneeweis DM, Schnapf JL (1995) Photovoltage of rods and cones in the macaque retina. Science 268:1053-1056.

Solomon SG, Lee BB, White AJ, Rüttiger L, Martin PR (2005) Chromatic organization of ganglion cell receptive fields in the peripheral retina. J Neurosci 25:4527-4539.

VanLeeuwen M, Fahrenfort I, Sjoerdsma T, Numan R, Kamermans M (2009) Lateral gain control in the outer retina leads to potentiation of center responses of retinal neurons. J Neurosci 29:6358-6366.

Verweij J, Kamermans M, Spekreijse H (1996) Horizontal cells feed back to cones by shifting the cone calcium-current activation range. Vision Res 36:3943-3953.

Verweij J, Hornstein EP, Schnapf JL (2003) Surround antagonism in macaque cone photoreceptors. J Neurosci 23:10249-10257.

Wiesel TN, Hubel DH (1966) Spatial and chromatic interactions in the lateral geniculate body of the rhesus monkey. J Neurophysiol 29:1115-1156.

Yagi T, Macleish PR (1994) Ionic conductances of monkey solitary cone inner segments. J Neurophysiol 71:656-665. 